\title{
Políticas de descentralização impactam negativamente a aprendizagem de professoras iniciantes
}

\author{
Silmara de Oliveira Gomes Papi \\ Universidade Estadual de Ponta Grossa \\ Pura Lúcia Oliver Martins \\ Pontifícia Universidade Católica do Paraná
}

\section{Resumo}

Este estudo foi direcionado para a investigação do processo de desenvolvimento profissional de professoras em início de carreira, atuantes nos anos iniciais do ensino fundamental de uma rede pública. Desenvolveu-se um estudo de caso de matriz crítico-dialética utilizando-se o grupo focal, a observação participante e a entrevista semiestruturada como instrumentos de coleta de dados. Os resultados revelam que o contexto de políticas descentralizadoras, em que as professoras estão inseridas, influencia negativamente seu desenvolvimento profissional. Essa constatação fornece uma visão sobre como tais políticas são assimiladas pelas iniciantes, contribuindo para o avanço dos estudos sobre 0 tema.

Palavras-chave: Professores iniciantes. Iniciação à docência. Desenvolvimento profissional. Políticas de descentralização. 


\section{Decentralization policies have a negative impact on the learning of beginning teachers}

This study is aimed at investigating the process of professional development of teachers at the beginning of their careers, working in elementary education in a public school system. A case study was conducted, based on a critical/dialectical approach, making use of the focal group, participating observation and semi-structured interviews, as instruments for data collection. The results reveal that the context of decentralizing policies in which the teachers are included negatively influences their professional development. This observation offers a vision of how such policies are assimilated by the beginners, contributing towards the advancement of studies on the subject.

Keywords: Beginner teachers. Teaching initiation. Professional development. Decentralization policies.

\section{Las políticas de descentralización causan un impacto negativo en el aprendizaje de profesoras principiantes}

Este estudio fue dirigido a la investigación del proceso de desarrollo profesional de profesoras en su inicio de carrera, actuantes en los años iniciales de una red pública. Se desarrolló un estudio de caso de matriz crítico-dialéctica utilizando un grupo focal, la observación participante y la entrevista semiestructurada como instrumento para colectar datos. Los resultados muestran que el contexto de políticas descentralizadoras en el cual las profesoras están inseridas, influye negativamente en su desarrollo profesional. Esa constatación ofrece una visión sobre cómo tales políticas son asimiladas por las principiantes, contribuyendo para el avance de los estudios sobre el tema.

Palabras-clave: Profesores principiantes. Iniciación a la docencia. Desarrollo profesional. Políticas de descentralización. 


\section{Introdução}

Os estudos sobre professores ${ }^{1}$ iniciantes têm avançado, especialmente na última década, em decorrência da crescente constatação da importância dos primeiros anos de exercício profissional para a aprendizagem do professor, seu desenvolvimento profissional, bem como para a permanência na profissão.

Em contraste com essa constatação, a atenção ao período de entrada na carreira não é ainda uma prática corrente nos processos formativos dos professores iniciantes brasileiros, embora iniciativas pontuais de programas de formação comecem a ser concretizadas na educação básica, conforme demonstram os estudos de André (2012) e Portella (2012), e, na educação superior, de acordo com o que apontam Stivanin e Zanchet (2012). No conjunto desses debates e encaminhamentos, entretanto, verifica-se a necessidade de estudos que evidenciem aspectos da aprendizagem da docência vinculada a contextos de políticas de caráter descentralizador.

0 presente estudo pretende contribuir para o aprofundamento das reflexões sobre o tema e objetiva sistematizar, a partir do campo da prática, elementos relacionados ao processo de desenvolvimento profissional de professores iniciantes, tendo em vista a apreensão das implicações existentes, para a aprendizagem da docência. Nesse sentido, permite compreender como políticas de descentralização são vivenciadas por professoras iniciantes, professoras que atuam nos anos iniciais do ensino fundamental, e, as repercussões desse processo em seu desenvolvimento profissional.

Para isso, após a apresentação da metodologia da investigação, desenvolvemse considerações sobre a etapa de iniciação docente e sua relevância para o professor. Em seguida são apresentados os resultados da pesquisa, por meio dos quais se evidenciam características do processo de desenvolvimento profissional das professoras envolvidas no estudo, em relação a um contexto de políticas de descentralização. Finalmente, são tecidas considerações sobre o período de iniciação e o desenvolvimento profissional das professoras iniciantes pesquisadas.

\section{Metodologia da investigação}

A pesquisa foi realizada mediante um estudo de caso (André, 2005) de matriz crítico-dialética (Thompson, 1981; Bernardo, 1991) que teve como eixo

1. Embora não se desconsiderem as questões de gênero, utiliza-se, na presente pesquisa, a palavra "professores" para designar profissionais tanto do sexo masculino, quanto feminino. Entretanto, a partir da definição dos sujeitos participantes do estudo de caso, por terem sido todos do sexo feminino, passa-se a utilizar também a indicação "professoras" quando se faz referência direta a elas, aspecto que inclui o título do artigo. 
epistemológico a concepção da teoria como expressão da prática (Autor, 2004; 2009), pois se considera que o conhecimento se constitui a partir da prática humana material e social sobre o mundo real, aspectos já ressaltados por Castoriadis (1985) e Thompson (1981). A abordagem do objeto de estudo se deu pelo enfoque qualitativo. (Lüdke; André, 2005)

$\mathrm{Na}$ fase exploratória da pesquisa, para a definição dos sujeitos participantes, foram utilizados como instrumentos de coleta de dados o grupo focal (André, 2005) e a entrevista semiestruturada. Na etapa central do estudo, já envolvendo as professoras selecionadas, utilizou-se a observação participante e a entrevista semiestruturada.

Duas professoras iniciantes, denominadas ficticiamente de Joana (Jo) e Luana (Lu), foram indicadas ${ }^{2}$ por pedagogas e diretoras de escolas municipais que participaram dos grupos focais (André, 2005), bem como por gestoras da Secretaria Municipal de Educação (SME) de um município do Estado do Paraná (por meio de entrevistas semiestruturadas), como professoras bem-sucedidas, um dos critérios para a seleção da unidade de estudo.

Diante do eixo epistemológico assumido, não se foi a campo com um conceito prévio de professor bem-sucedido, mas se buscou apreender a concepção existente entre as gestoras. Assim, constatou-se na investigação que, para as participantes, professores bem-sucedidos são inovadores, relacionam-se bem com os alunos, buscam a própria formação, responsabilizam-se pelo processo ensino-aprendizagem, trabalham com a diversidade e socializam novas práticas pedagógicas.

Tais características, analisadas em si mesmas, podem mostrar-se relevantes; entretanto, quando consideradas na relação com os elementos do contexto de nível micro, meso e macrossocial relacionados à educação e às escolas pesquisadas, revelam as contradições existentes, pois em diferentes situações indicam que tal valorização se dá em detrimento da aprendizagem da docência e dos processos de transformação social. Mostram-se vinculadas principalmente à reestruturação da escola para atender à abordagem mercadológica vinculada à educação nos últimos anos, que buscam a diminuição de custos, a redefinição de gastos e o controle centralizado dos resultados, o que caracteriza, para Oliveira (2006), uma flexibilização mediada pela descentralização.

2. Solicitou-se a pedagogas e diretoras, em grupos focais, a indicação de professores iniciantes considerados por elas como bem-sucedidos. Representantes da SME também compuseram esse processo. A opção pela participação das gestoras, que teve como finalidade a definição da unidade de estudo, levou em consideração que as relações estabelecidas na escola pelos professores têm traços importantes da presença dos gestores e dos mecanismos de controle sobre o trabalho docente, embora se tenha considerado também que esse processo pode suscitar nos docentes iniciativas de oposição à forma de organização e às condições de trabalho existentes. 
De acordo com o recorte da pesquisa, as pedagogas e diretoras participantes dos grupos focais pertenciam a escolas em que havia professores iniciantes atuando nos anos iniciais do ensino fundamental, considerados com o tempo de até cinco anos de exercício profissional (Imbernón, 1998) e sem experiência anterior no magistério.

A observação das professoras selecionadas foi realizada pela pesquisadora em suas escolas, de uma a duas vezes por semana, durante quatro meses. Elas foram acompanhadas nas diferentes atividades, desde o horário de entrada até o momento de saída dos alunos. Além disso, foram acompanhadas também na hora-atividade, dedicada ao planejamento docente, em reuniões de pais e em dias de reunião pedagógica, denominadas pelas escolas como dias de organização do trabalho pedagógico (OTP).

Após o período de observação, para complementar o material empírico registrado nos diários de campo da pesquisadora (Diape), foram realizadas individualmente com as professoras três entrevistas semiestruturadas com duração aproximada de uma hora e quinze minutos cada uma delas. 0 material obtido nas entrevistas foi transcrito, tendo em vista sua leitura e análise qualitativa. (André, 2005; Lüdke; André, 2005)

0 conjunto dos dados coletados permitiu a percepção de elementos que se articulam ao desenvolvimento profissional das professoras iniciantes, evidenciando aspectos da aprendizagem da docência a partir da prática que vivenciam.

\section{Período de iniciação e desenvolvimento profissional docente}

O período de iniciação docente é uma etapa que se destaca no percurso profissional dos professores, tais são as particularidades vivenciadas por eles e as necessidades práticas e formativas que apresentam. (Marcelo, 1999; 2006)

Nesse período, sentimentos de insegurança ocasionados pelo que é considerado novo, ou pela percepção do próprio protagonismo no processo de ensinar (Corsi, 2005; Nono; Mizukami, 2006), somados à incerteza gerada por conflitos vividos na relação com os alunos (Corsi, 2005) e com as famílias, surgem no professor desencadeando formas de agir e pensar que interferem na aprendizagem da docência.

0 período de iniciação, que corresponde aos cinco primeiros anos de exercício profissional (Imbernón, 1998), é decisivo para a continuidade na profissão e para o encaminhamento das ações profissionais futuras, pois nele se constituem as bases do conhecimento específico, construídas pelo professor na condição de iniciante. É, portanto, um período de intensas aprendizagens. 
Esse conhecimento, que se consolida a partir da ação docente, envolve também as condições objetivas da escola e as situações determinantes vivenciadas, pois, conforme demonstram estudos clássicos sobre o período de entrada na profissão (Jordell, 1987), se a influência dos alunos na aprendizagem do professor iniciante é relevante, maior relevância têm os fatores estruturais, que funcionam como molduras que buscam imprimir determinada forma a esse processo.

Isso permite inferir que as possibilidades existentes na escola, na medida em que se articulam à tarefa de ensinar e aprender a ensinar, vivida simultaneamente pelo professor iniciante, influenciam seu desenvolvimento profissional, pois colaboram para constituir formas de agir e de compreender a profissão.

Considera-se o desenvolvimento profissional docente um processo de melhoria no ensino e de aprendizagem constante que se efetiva pela reflexão sobre as situações vivenciadas, bem como pela análise - à luz de um corpus teórico - das ações e processos empreendidos e respostas obtidas. Ele efetiva-se em um contexto de dúvidas e necessidades, que geram encaminhamentos de ordem teórico-prática pelo professor. Além disso, o desenvolvimento profissional poderá ser mais efetivo se as situações formativas experimentadas forem favoráveis à aprendizagem docente. Por isso é um processo que possui múltiplas dimensões. (Marcelo, 1999)

Nesse contexto de aprendizagem profissional, entretanto, entende-se que o professor não é apenas um sujeito determinado pelas condições objetivas às quais se encontra submetido, sendo capaz, também, em alguma medida, de ser determinante do contexto e de suas próprias ações, tal como entende Thompson (1981) sobre a possibilidade humana. Para o autor, o que existe é apenas uma relativa determinação do sujeito, pois não se pode esquecer que há uma “[...] ambivalência crucial de nossa presença humana em nossa própria história, parte sujeitos e parte objetos, agentes voluntários de nossas próprias determinações involuntárias." (Thompson, 1981, p. 101)

Daí entender-se que o professor é também protagonista da sua história e que, em meio às contradições existentes, sua prática pode assumir contornos diferenciados e imprevistos, pois vivencia uma realidade em que há possibilidades opostas coexistentes. (Thompson, 1981)

\section{Resultados e discussão dos dados}

Considerando-se que o desenvolvimento profissional docente se efetiva em um contexto em que circunstâncias materiais determinam as relações sociais básicas a partir das quais se organiza a sociedade, fatores de ordem política, econômica 
e social apresentam-se, nesse contexto, em relação de reciprocidade, pois se encontram na dinâmica que constitui o conjunto da vida social. (Bernardo, 1991)

Isso faz com que compreender o desenvolvimento profissional signifique considerar que ele se articula, ainda que não exclusivamente, aos determinantes do sistema capitalista.

Diante desse entendimento, analisar o desenvolvimento profissional das professoras selecionadas para o estudo - Joana (Jo) e Luana (Lu) - significa considerar que elas se constituem como professoras inseridas em uma escola de uma rede pública municipal de ensino e que possuem alunos concretos e dificuldades e facilidades que se manifestam no seu dia a dia. Significa entender que elas se constituem como professoras nas relações sociais, mediante as instituições em que se inserem, sendo esse um processo situado historicamente que expressa tal momento histórico, e não outro qualquer. (Autor, 2004; 2009)

0 desenvolvimento profissional das professoras efetiva-se em um contexto em que ocorrem mudanças importantes em todos os setores para viabilizar o processo de reestruturação capitalista, que lança mão de novas tecnologias e formas de organização para garantir sua manutenção, alçando o âmbito da educação e da escola. (Santos, 2004)

Para Santos (2004), desses novos contornos do capitalismo, decorre 0 determinante básico das novas características de relacionamento social e das inovações que facilitam diferentes possibilidades ao mercado, bem como dos novos desenhos da formação de trabalhadores e capitalistas, para esse contexto. Para o autor, as práticas sociais e escolares constituem novos significados e conceitos a partir do critério de produtividade de viés mercadológico, pois “assim se estrutura o campo básico da educação como processo social." (Santos, 2004, p. 17)

$\mathrm{Na}$ esteira desse entendimento é que, na análise dos dados de campo, são verificados indicativos da transferência do modelo empresarial de gestão, para o âmbito da educação, tal como demonstrado por Bruno (2006) e Santos (2004). Os autores destacam que na ordem capitalista atual, embora surjam modelos que aparentam maior flexibilidade, bem como ações descentralizadas que parecem ampliar o sentimento de autonomia, o que existe concretamente é a centralização das decisões, verificando-se maior preocupação com o resultado do que com o processo pelo qual ele se institui.

Esse tipo de encaminhamento, segundo Shiroma e Campos (2006), se refere a um modelo de gestão tecnocrática, que busca dar novo significado ao ideário de democracia escolar mediante a prática do gerencialismo. Ele se configura pela manutenção de uma unidade de gestão mais ampla, articulada a outras unidades menores, efetivando-se, assim, pelo controle centralizado dos resultados.

Tal encaminhamento, estruturado a partir de uma visão economicista da 
educação, é entendido pelas instâncias superiores como uma possibilidade de melhoria na gestão dos processos e escassos recursos financeiros destinados a ela.

Inseridas nesse contexto, as professoras constituem o desenvolvimento profissional, que expressa a prática que vivenciam. Trata-se, assim, da compreensão de como se constituem como professoras na condição de iniciantes, em determinado contexto histórico.

\section{A construção de uma percepção minimizada da função docente}

Os dados de campo deste estudo, obtidos por meio das observações e entrevistas realizadas, indicam que no período de iniciação profissional as professoras demonstram construir uma percepção minimizada da função docente, o que se efetiva à medida que são submetidas à execução de atividades impositivas, repetitivas e burocratizadas.

Essas atividades são contínuas e correspondem ao preenchimento de fichas/papéis, sem que as professoras demonstrem compreender a finalidade dessa demanda, ou mesmo sem que questionem sua relevância para a prática pedagógica. Durante a observação, verificou-se o preenchimento de fichas dos alunos para o controle de tarefas, de frequência (com a contabilização de faltas justificadas e não justificadas, para além do livro de chamada regular), de livros lidos (literatura infantil) e, ainda, de leitura (língua portuguesa), para a entrega posterior às pedagogas das escolas. Além disso, não se constataram indicativos da participação das professoras no processo decisório de implantação dessas fichas, indicando um modelo centralizado de gestão.

As professoras evidenciaram desconhecimento quanto à finalidade de tal prática, quando afirmaram que “... a pedagoga deve contar e guardar..." (Jo) os números apresentados nas fichas, ou ainda, que com os dados “... não era feito nada, que era somente para a pedagoga fazer um levantamento, passar para a SME, e que, ao final do ano, 'decerto é jogado tudo fora'." (Diape 2, Lu)

0 preenchimento regular de dados quantitativos conduziu as professoras a utilizarem o tempo/espaço de que dispunham na escola para a hora-atividade (quando dispunham, especialmente no caso de Luana), para o cumprimento de exigências que revelaram as formas de controle e a burocratização a que estão submetidas, conforme se verifica no excerto de um dos depoimentos de Joana:

... além do livro de chamada, tem uma chamada fixada na parede, tem que fazer todo dia, que ela fica lá pras pessoas da Secretaria, ... parece que foram elas que repassaram 
isso, você faz a chamada e tem também na parede. Aí é assim: tem todos os nomes deles, aí, além do livro de chamada, faz aquela chamada lá também, porque... facilita 0 trabalho da pedagoga, que no final de cada mês ela tem que fazer, quantas faltas tem, quantas não tem, .... 0 verde..., é presença. 0 amarelo é [falta] justificada, o vermelho é quando [o aluno] falta e o azul é quando está, mas não realizou a tarefa ... Aí ela faz uma contagem, que eu acho que ela manda pra Secretaria. Aí tem também dos livros que nós tínhamos que ler..., pra ver se eles gostaram e a gente marcava na fichinha... Tem outra que a pedagoga... pede, que é pra ver quantos alunos aprenderam, quantos leem, quantos estão no caminho. (Jo)

A postura das professoras indica certo ajustamento à situação, ou, conforme evidencia Bruno (2006), a assimilação de tais tarefas por elas. Essa postura é verificada, também, quando Luana ressalta que foi criticada, em sua escola, a inviabilidade do modelo de fichas disponibilizado aos professores, e não a própria existência dessa exigência ou de suas condições de realização. Luana, nesse sentido, indica como uma conquista relevante dos professores o fato de que, ao ser questionado o formato das fichas recebidas, e, após muita insistência, elas “... foram diminuindo de tamanho..." (Lu)

A postura de aceitação das exigências, pelas professoras, demonstra que a experiência vivenciada por elas (Thompson, 1981) favoreceu a percepção da função docente relacionada à de profissionais executantes de tarefas determinadas externamente, o que é verificado pela forma como seguem e concordam com tais determinações.

Embora Luana tenha feito referência, durante as entrevistas, à sobrecarga de trabalho, sobressaiu-se mais intensamente em sua fala o fato de que 0 grupo de professores questionou, essencialmente, a forma como as exigências foram concretizadas, o tipo de material utilizado, e não, mais profundamente, suas intenções ou relevância. Isso evidencia a preponderância da assimilação da lógica de racionalidade existente (Bruno, 2006) e um processo que denuncia a aprendizagem da professora iniciante via ajustamento interiorizado, tal como analisado por Marcelo (1999).

\section{O cumprimento de metas e o resultante entendimento da prática pedagógica como uma prática determinada externamente}

Relacionada à construção de uma percepção minimizada da função docente, a existência de metas a serem alcançadas pelas professoras facilitou o entendimento da profissão como dependente de determinações externas. Evidenciou-se o 
cumprimento de metas relacionadas à leitura de livros infantis e à frequência dos alunos à escola, bem como se verificou a atribuição às professoras, sob quaisquer condições existentes, da responsabilidade pelos resultados a serem alcançados diante dessas metas.

Nesse contexto, Joana e Luana adaptaram sua prática pedagógica buscando atender às diferentes exigências, como se observou quando da preocupação de Luana em descobrir a quantidade de livros estabelecida como necessária pela $\mathrm{SME}$, e quando buscou alternativas para que seus alunos realizassem a leitura daquela quantidade.

Influenciada por exigências externas, Luana deixou de priorizar aspectos necessários para o processo ensino-aprendizagem dos alunos, como, por exemplo, a vinculação ao prazer pela leitura. Ela relata com apreensão que desconhecia a quantidade de livros que deveriam ser lidos por eles e, ao mesmo tempo, que continuamente não alcançava as metas estabelecidas, aspecto constante no relatório anual recebido da Secretaria Municipal de Educação.

Entretanto, após diferentes encaminhamentos para atender tal exigência, Luana ressalta ter compreendido que, se os alunos realizassem a atividade de leitura uma vez por semana, conseguiria atingir a meta, mas, caso contrário, teria que fazer a atividade ao menos duas vezes na semana seguinte, ou “... dar o livro para a criança levar para casa, para ir atingindo as metas..." (Lu)

Com tal posicionamento, Luana indica o seguimento prioritário e aleatório das ordens, independentemente das necessidades surgidas no desenvolvimento da prática pedagógica. Pressionada pelo alcance das metas estabelecidas externamente à escola, desencadeou-se, na professora, uma prática que se naturalizou mediada pela coação, além de que, diante dos alunos, ficou obscurecida - pelo caráter impositivo e coercitivo que assumiu a atividade - a importância da leitura como uma atividade formativa, além de prazerosa.

Isso foi verificado na observação feita em sala de aula, quando Luana declarou aos alunos, em tom forte e apreensivo, que “... têm que pegar um [livro] que ainda não leram" e que "'a gente não escolhe os livros pela capa, escolhe pelo título"." Luana afirmou, ainda, que não adiantava pegarem um livro fino ou pequeno, porque "têm que ler e continuar sentado, nem que leia mais vezes [...]." (Diape 6, Lu)

Seguindo a ordem recebida, Luana vivencia um processo formativo que se contrapõe à expectativa da formação de um professor a quem, desde o período de iniciação, são propiciadas possibilidades de desenvolvimento profissional que favorecem a construção da autonomia e a troca entre os pares, tal como indicado como relevante pelos estudos da área (Marcelo, 1999; 2006), sobre a aprendizagem da docência .

0 alcance de metas pode ser compreendido também como determinante da 
prática das professoras e da aprendizagem docente, quando se verifica em Luana a preocupação com o número de faltas não justificadas dos alunos, apresentado à SME, e, diante disso, a percepção da necessidade de diminuir esse número.

A professora e a escola buscaram critérios mais flexíveis, que mudassem a forma de serem consideradas as faltas como justificadas ou não, pela escola, o que alteraria o número final de ausências não justificadas. Deixou de estar em questão, para Luana, a ausência dos alunos e a implicação de suas faltas no processo de aprendizagem, pois se verificou apenas a preocupação com o número de faltas que retornava no relatório final da SME e a indicação do não alcance das metas.

Luana deixou de vivenciar práticas que envolvessem a discussão e a problematização com outros professores, uma realidade que se opõe às evidências que indicam a importância, para o desenvolvimento profissional e a aprendizagem da docência, do estímulo à busca de alternativas para os desafios encontrados no processo ensino-aprendizagem, numa perspectiva de relação entre a prática, a teoria já constituída e a construção de uma nova prática. (Imbernón, 1998; Marcelo, 1999; Nóvoa, 2002)

Joana também vivenciou a definição externa de sua prática pedagógica, aspecto percebido na angústia demonstrada por ela frente aos pais, diante da tarefa incondicional de alfabetização dos alunos. Nesse contexto não foi considerado pela SME, pela escola, ou mesmo pela professora, como um elemento interferente nos resultados exigidos, o fato de que Joana era responsável por um grupo de 31 crianças do primeiro ano do ensino fundamental, com idades de cinco/seis anos, que se mantinham dispersas durante as atividades propostas, fato ocasionado, inclusive, pela inadequação ergonômica do mobiliário da sala de aula para os alunos.

Tal inadequação levava-os a posicionarem constantemente os joelhos sobre a cadeira, dificultando sua atenção e provocando na professora a sucessiva correção dos alunos, sem a evidência de que percebia o motivo de tal comportamento, conforme se observa nos registros dos diários de campo:

A professora pede a um aluno que está de joelhos na cadeira para que se sente a fim de não atrapalhar... E fala a todos: 'Para quem já terminou, vamos ler as vogais'. (Diape $5, \mathrm{Jol}$

- 'Pronto? Sentem com a poupança na cadeira. ... Vamos fazer a leitura do alfabeto'. (Diape 13, Jo) 
Sem compreender mais profundamente as dificuldades vivenciadas, e demonstrando preocupação com a exigência da alfabetização dos alunos durante uma reunião de pais, Joana pediu-lhes que compreendessem o fato de que ela não tem tempo de enviar tarefa para casa mais do que duas vezes por semana e solicitou que colaborassem com ela, conversando com os filhos sobre a indisciplina na sala de aula.

Na reunião, Joana alertou os pais sobre o fato de que teriam afirmado que ela grita com os alunos, mas defendeu-se, ressaltando: “... eu não grito, eu ergo o tom de voz..." (Diape 7, Jo) e complementou, em seguida: “... 'Gente, eu tenho que alfabetizá-los, pelo menos é isso que a Secretaria está pedindo'." (Diape 7, Jo)

Demonstrando a não percepção da falta de condições para atingir o esperado, Joana assumiu pessoalmente a responsabilidade pelas dificuldades encontradas. Ela deixou de colocar em questão elementos indissociáveis de sua prática, que revelam as contradições existentes: metas a serem alcançadas $x$ número de alunos em sala de aula $\mathrm{x}$ idade dos alunos $\mathrm{x}$ ausência de uma política de formação e acompanhamento a professores iniciantes na rede pública municipal.

Sem condições de viabilizar o esperado, possivelmente pelo número de alunos que possui e a decorrente dificuldade para desenvolver uma prática compatível com a faixa etária em que eles se encontram, somada ao fato de ser uma professora em início de carreira, Joana demonstrou sua insegurança aos familiares sem, entretanto, manifestar compreender mais profundamente a complexidade da situação.

As metas estabelecidas pela SME incidiram objetivamente sobre a prática das professoras iniciantes e seu processo de aprendizagem da docência, pois, ao mesmo tempo em que elas se dedicaram ao alcance das diferentes metas sob quaisquer condições e sem terem participado da sua concepção e definição, permitiram também que sua prática pedagógica fosse conduzida externamente, pois as tomaram como norteadoras do trabalho desenvolvido com os alunos.

Tal processo indica que não thes foi favorecido um modelo participativo em nível de tomada de decisões e de estabelecimento de prioridades e necessidades em nível de escola, evidenciando a importância atribuída às decisões advindas das instâncias centrais de gestão da educação.

\section{A construção de uma visão simplificada da avaliação da aprendiza- gem discente mediada por políticas de avaliação externa}

Pressionadas pelo modelo avaliativo existente no contexto de trabalho, Joana e Luana vinculam estreitamente sua prática pedagógica à participação dos alunos 
na avaliação externa, assim denominada a avaliação realizada pela Secretaria Municipal de Educação em parceria com o Instituto Ayrton Senna - Programa Circuito Campeão ${ }^{3}$. Tal prática avaliativa desenvolvida pela Secretaria nos anos iniciais da educação básica remete a políticas regulatórias e ao contexto dos pressupostos de um modelo de Estado avaliador. (Yannoulas; Oliveira, 2013)

A existência desse modelo confirma o que foi demonstrado por Almeida, Leite e Santiago (2013) sobre a condição existente na transição do século XX para o XXI sobre as políticas voltadas à formação de professores em sua relação com o ensino fundamental, mas avança em relação a essa constatação, demonstrando que a existência dessas políticas adentra com significância neste último século, tal como verificado no município pesquisado.

No contexto das avaliações em larga escala, as professoras se mostraram inseguras, frente às cobranças e aos resultados a serem alcançados pelos alunos, e buscaram alternativas para superar o clima de medo existente. Tais alternativas, que demonstraram seu esforço e o imperativo de acatar as exigências, contraditoriamente tanto atenderam à necessidade de sobrevivência na profissão, quanto favoreceram a construção de uma visão simplificada do processo de avaliação da aprendizagem discente, uma vez que passaram a ser compreendidas pelas professoras como naturalmente vinculadas a esse processo.

Os desafios vivenciados levaram Joana e Luana a adotarem práticas que se tornaram correntes. Luana destacou que, à medida que teve maior familiaridade com a avaliação do Instituto Ayrton Senna, passou a compreender seus encaminhamentos e objetivos, desenvolvendo a prática pedagógica tendo-os como norteadores. Assim, além de ter ressaltado que “... aí você, professor, trabalha em cima daqueles objetivos" (Lu), Luana também descobriu que as questões da avaliação eram relativamente previsíveis, pois, segundo ela, se em uma das provas os organizadores “... querem que a criança faça contagem, aí tem lá um saco de bolinhas, na outra vez tem um prato de doce..." (Lu)

Luana declarou ter ficado menos apreensiva em relação à avaliação do que inicialmente ficava, quando percebeu que os exercícios existentes mostravam-se, em linhas gerais, os mesmos a cada avaliação, apresentando apenas pequenas variações que não alteravam seu sentido e nível de exigência. 0 que também chamou a atenção foi a prática pedagógica das duas professoras, que passaram a repetir os modelos de exercício da prova, buscando garantir o esperado resultado "positivo" dos alunos.

Para Luana a repetição dos exercícios é necessária, pois declara que, caso

3. Sobre o Programa Circuito Campeão do Instituto Ayrton Senna, consultar: http://senna.globo.com/ institutoayrtonsenna/programas/programas_circuitocampeao.asp. Ainda, sobre a parceria público-privada e suas implicações para a gestão da escola pública, consultar Peroni, Oliveira e Fernandes (2009). 
contrário, os alunos serão prejudicados. Assinala que não adianta trabalhar com a criança, “... ficar fazendo uma atividade... só uma atividade que não vai ser cobrada na prova, porque virá... outra avaliação além da que você faz." (Lu)

Ela afirma, ainda:

Se eu vejo que vem a avaliação externa, que cobra que o meu aluno associe lá número e quantidade, que ele resolva problema, que ele resolva continha com dois números, multiplicação, e eu não trabalho com ele, eu não preparei ele pra prova, o que adianta eu não preparar ele? Então..., prepará-lo, pra ele enfrentar. (Lu)

Demonstrando entendimento semelhante ao de Luana sobre a avaliação externa, Joana impeliu seus alunos de cinco e seis anos a resolverem uma atividade proposta por ela, afirmando, diante da negação feita por alguns deles, que tinham de realizar os exercícios, pois “... é um modelinho de prova que veio da prefeitura, [necessário] porque provavelmente vão fazer prova na semana que vem..." (Diape 10, Jo), referindo-se à avaliação do Instituto Ayrton Senna.

Assim, também valorizando a repetição de exercícios para a realização da prova, Joana destaca que a pedagoga da escola guarda avaliações para serem usadas posteriormente pelos professores, a fim de que verifiquem em quais conteúdos seus alunos “... estão mais fraquinhos..." (Jo) e de que trabalhem a partir “... do que está faltando." (Jo)

As ações das professoras e da escola são compreendidas considerando-se as contradições das políticas de avaliação externa implementadas nas últimas décadas, que correspondem às novas regulações das políticas educacionais na América Latina, regulações que trazem mudanças importantes para as condições de trabalho nas escolas e as formas de gestão escolar, impactando em uma nova estruturação do trabalho docente, conforme Oliveira (2006).

Essa nova estruturação, de acordo com o que foi constatado na presente investigação, resulta, inclusive, em uma nova conformação da aprendizagem profissional, que se vê coagida a sujeitar-se às suas demandas, em detrimento de um processo que vise à formação docente numa perspectiva integral, nos âmbitos técnico, humano e político.

As exigências às quais são submetidas as professoras conduzem-nas a uma prática que favorece a aprendizagem simplificada do desenvolvimento do currículo, além da limitação do desenvolvimento profissional, em que a repetição de exercícios passa a ser entendida como referencial da aprendizagem dos alunos. Tal política de avaliação, ao desencadear esse entendimento nas professoras, reforça a conclusão de Esteban (2012) de que as avaliações em larga escala, guiadas pela mensuração e estabelecimento de metas, sustentam processos mais vinculados à 
gestão educacional do que à aprendizagem discente. Ao simplificarem processos complexos, retiram

... da reflexão e do debate aspectos indissociáveis à ação escolar, aos processos de aprendizagem, aos projetos de ensino e aos posicionamentos dos sujeitos em relação aos seus resultados globalmente considerados, não apenas sujeitos hierarquicamente posicionados segundo seus desempenhos. (Esteban, 2012, p. 576)

Aos elementos destacados pela autora, somam-se, portanto, as implicações na aprendizagem profissional docente, pois o que Joana e Luana, na etapa de iniciação profissional, compreendem como válido é a expressão do que vivenciam nesse momento histórico, isto é, ações regulatórias em que alunos, professores e escolas são avaliados e comparados entre si, independentemente das condições socioculturais e dos possíveis investimentos em educação necessários.

\section{A centralidade da responsabilização pessoal pelo processo ensino- aprendizagem atribuída às professoras}

A percepção das relações estabelecidas por Joana e Luana na escola, bem como das conexões entre os vários elementos, evidenciou que as professoras deparam com múltiplos encaminhamentos no processo de aprender a ensinar, o que se efetiva em meio a contradições, continuidades e rupturas.

As demandas burocratizadas e regulatórias a que estão submetidas revelam os mecanismos impostos pelas instâncias de gestão da educação municipal que conduzem à sua responsabilização pessoal pelo processo ensino-aprendizagem, em detrimento da igual observância, por parte dessas instâncias, das condições objetivas que viabilizem o desenvolvimento do trabalho pedagógico e a aprendizagem da profissão no período de iniciação.

Verificou-se que a centralidade da responsabilização pessoal e o que isso poderia acarretar às professoras iniciantes conduziu-as a um processo de aprendizagem docente que vai de encontro ao desenvolvimento profissional vinculado a avanços, tendo em conta a promoção da escola e sua melhoria, a inovação curricular, o desenvolvimento do ensino e da profissionalidade docente, aspectos ressaltados por Marcelo (1999) como articulados ao desenvolvimento profissional.

Verificou-se que não se favoreceu a Luana e Joana o desenvolvimento profissional desde uma perspectiva coletiva, que passa tanto pela mudança do professor como pessoa e profissional, quanto pela construção de uma visão ampliada do ensino e do exercício da profissão, que vai além do espaço da sala de aula e compreende a 
escola como elemento inter-relacionado a outros condicionantes objetivos cujos determinantes advêm, inclusive, de demandas econômicas.

A exigência do preenchimento constante de diferentes fichas, bem como a direção externa da prática pedagógica e a cobrança da submissão a processos de avaliação que exaltam exclusivamente a lógica de resultados - além da valorização da competitividade em detrimento da colegialidade, pela SME e pela escola são encaminhamentos que favoreceram a assimilação de tais ordenamentos e a consequente responsabilização exclusiva das professoras pelo processo educativo. Tal como evidenciado por Bruno (2006, p. 105), verificou-se que

A lógica da racionalidade/produtividade copiada das organizações empresariais penetra no ambiente cotidiano das escolas e das universidades, em um primeiro momento, por imposição dos órgãos de controle dos sistemas de ensino estatais. Logo, por assimilação.

Os dados evidenciam, portanto, uma prática social em que se demonstra haver maior valorização daqueles que ocupam cargos de gestão, fazendo com que os demais sejam executantes das metas externamente propostas, na perspectiva de exercerem a função de técnicos obedecentes.

\section{Em contraposição ao modelo existente, a necessidade do trabalho coletivo e da colaboração evidenciada pelas professoras pesquisa- das}

Para além das condições de trabalho existentes, e, antagonicamente ao que foi proporcionado às professoras, os dados demonstraram também que elas agem/ reagem em diferentes momentos em relação a esses determinantes, expressando formas embrionárias que revelam suas necessidades no período de iniciação, em relação ao desenvolvimento profissional. Suas ações constituem-se como formas de resistência ou possibilidades alternativas que se estabelecem em meio às contradições existentes. (Autor, 2009; Santos, 2004)

Joana e Luana evidenciaram a possibilidade de práticas autônomas que thes asseguraram, inclusive, a continuidade do trabalho. Isso é observado quando, em resposta ao isolamento muitas vezes vivenciado, as professoras buscaram seus pares, estabelecendo relações em que procuraram redefinir sobre outras bases 0 funcionamento da escola, conforme se verifica nos excertos a seguir: 
[...] geralmente é iniciativa da gente, de estar dividindo, fazendo um trabalho conjunto, não que a escola favoreça tanto. E se a escola ainda não favorecer pra gente ficar planejando no mesmo horário, é mais difícil, tem que ir à sala, ver, trocar,... (Lu)

[...] A gente se troca, atividade, assim, importantíssimo... Atividades, uma troca com a outra,... Ah, às vezes na hora-atividade, como a A. [professora] veio aqui, quando a gente sabe que alguém está na hora-atividade, ou às vezes vai à sala entregar. (Jo)

Além de buscarem, por iniciativa própria, formas de socialização e troca com os demais professores, Luana ainda evidencia que valoriza a experiência e a capacidade dos colegas da escola, buscando sua participação e ajuda para suprir as dificuldades existentes, peculiares à sua condição de iniciante. Ela afirma:

Mas nas dificuldades eu sempre procuro ajuda, pergunto pra alguém que sabe mais,... que tenha mais experiência..., compartilhando a dúvida. (Lu)

As professoras procuraram determinar por meio de sua atividade, de forma explícita ou implícita, como afirma Castoriadis (1985), o conteúdo das relações em que estão envolvidas, não sendo apenas determinadas por elas. Criaram outro modo de funcionamento da escola, cujo viés articulador é a referência ao coletivo, tal como os trabalhadores em suas práticas.

Assim como constatado por Santos (1992; 2004) em uma análise da dinâmica dos processos socioeconômicos e dos movimentos sociais, os trabalhadores criam relações sociais baseadas no coletivo e na horizontalidade, opostas às relações estabelecidas pelo modo de produção capitalista, em que preponderam a hierarquia, o individualismo, a competitividade e a passividade. As relações baseadas no coletivo e na horizontalidade são práticas que surgem isoladas, pois “... refletem a fragmentação imposta pelo capitalismo à classe trabalhadora." (Santos, 1992, p. 134)

A esse tipo de relações sociais, Santos (1992; 2004) denomina de relações sociais de tipo novo, e, assim como Bernardo (1991), entende que tais relações constituem uma forma alternativa que se contrapõe ao modelo vivido sob o capitalismo, na medida em que se mostram capazes de instituir outras formas de organização social.

$\mathrm{Na}$ complexidade do dia a dia escolar, as professoras demonstram que vivem relações sociais antagônicas. De um lado, estão as que correspondem à forma como a organização escolar se constitui e que conduzem a modelos hierárquicos, concorrenciais e passivos; de outro, estão relações pelas quais as professoras negam essa forma de organização, que correspondem à necessidade de criação 
de outras possibilidades para a prática, opostas às primeiras, ainda que se manifestem proporcionalmente simplificadas, em face das demandas existentes.

De forma potencial, Joana e Luana sinalizam que a colaboração e o desenvolvimento do coletivo são necessidades para seu processo de desenvolvimento profissional, podendo contribuir para a melhoria da prática profissional e, em decorrência disso, da educação daqueles que se beneficiam dela.

\section{Conclusões}

Este estudo evidenciou que a imposição de políticas de descentralização sobre a prática pedagógica de professoras iniciantes influenciou negativamente seu processo de aprendizagem da docência, e, portanto, seu desenvolvimento profissional. As professoras foram impelidas a constituir uma percepção minimizada da função docente, relacionada ao desenvolvimento da prática a partir de determinações externas. Nesse mesmo contexto, em decorrência das diferentes exigências, constituíram, também, um entendimento limitado acerca da avaliação discente, entendimento relacionado à percepção da sua responsabilização pessoal pelo processo ensino-aprendizagem, em detrimento da consideração, pelas instâncias superiores e pelas próprias professoras, às condições objetivas existentes, aspectos que igualmente influenciam esse processo.

Contraditoriamente, verificou-se que Joana e Luana empreenderam iniciativas que se mostraram, em alguma medida, determinantes dessa mesma realidade. Elas instituíram movimentos em que evidenciaram que, para além do atendimento às premissas existentes, são protagonistas de sua própria história, tal como entende Thompson (1981) sobre as possibilidades da ação humana. Essas iniciativas revelaram necessidades vinculadas à aprendizagem da docência, a partir da sua condição de iniciantes na profissão, um processo historicamente situado. As professoras demonstraram que a troca entre os pares, a colaboração e a valorização de professores mais experientes são aspectos relevantes no período de iniciação na docência.

Não se pretendeu, com este estudo, esgotar as possibilidades de compreensão do processo de desenvolvimento profissional das professoras pesquisadas, pois a realidade é contraditória e está em permanente movimento. Entretanto, verificouse que a experiência vivida por Joana e Luana tem marcas dos determinantes sociais e das ações burocratizadas e regulatórias que exercem impacto sobre a aprendizagem da docência, especialmente em decorrência de políticas de avaliação externa e de mecanismos de gestão de viés economicista, que são aparentemente 
flexíveis.

Os dados evidenciados podem subsidiar reflexões sobre propostas direcionadas a professores em início de carreira e seu processo de desenvolvimento profissional, principalmente frente a políticas de descentralização. Colaboram para a concretização de políticas educacionais voltadas a essa etapa profissional, que favoreçam a compreensão e superação das adversidades da aprendizagem e do exercício da profissão, tendo em vista que o professor e sua prática pedagógica são elementos que precisam relacionar-se aos propósitos de uma educação democrática e emancipatória.

\section{Referências}

ALMEIDA, Lucinalva; LEITE, Carlinda; SANTIAGO, Eliete. Um olhar para as políticas curriculares para a formação de professores no Brasil e em Portugal na transição do século XX para o século XXI. Revista Lusófona de Educação, Lisboa, v. 23, n. 23, 119-135. 2013. Disponível em: <http://revistas.ulusofona.pt/index.php/ rleducacao/article/view/3357>. Acesso em: 10 ago. 2013.

ANDRÉ, Marli Eliza Dalmazo Afonso de. Estudo de caso em pesquisa e avaliação educacional. Brasília: Líber Livro, 2005.

Políticas e Programas de Apoio aos Professores Iniciantes no Brasil. In: Congreso Internacional sobre Profesorado Principiante e Inserción Profesional a la Docencia, 3, 2012, Santiago do Chile, Anais..., Santiago do Chile: UA. 1 Cd-Rom. BERNARDO, João. Economia dos conflitos sociais. São Paulo: Cortez, 1991.

BRUNO, Lucia. Educación y poder. In: FELDFEBER, Myriam; OLIVEIRA, Dalila Andrade. (Comps.). Políticas educativas y trabajo docente. Buenos Aires: Centro de Publicaciones Educativas y Material Didáctico, 2006. 91-109.

CASTORIADIS, Cornelius. A experiência do movimento operário. São Paulo: Brasiliense, 1985.

CORSI, Adriana Maria. Professoras iniciantes: situações difíceis enfrentadas no início da prática docente no ensino fundamental. 2005. Disponível em: <http:// www.anped.org.br>. Acesso em: 11 jul. 2010.

ESTEBAN, Maria Teresa. Considerações sobre a política de avaliação da alfabetização: pensando a partir do cotidiano escolar. Revista Brasileira de Educação, Rio de Janeiro, ANPEd, v. 17, n. 51, 573-743, set.-dez. 2012.

IMBERNÓN, Francisco. La formación y el desarrollo profesional del profesorado: hacia una nueva cultura profesional. 3. ed. Barcelona: Graó, 1998.

JORDELL, Karl Oynvind. Structural and Personal influences in the Socialization of Beginning Teachers. Teaching \& Teacher Education, 3 (3), 1987. 165-177. 
LÜDKE, Menga; ANDRÉ, Marli Eliza Dalmazo Afonso de. Pesquisa em Educação: abordagens qualitativas. São Paulo: EPU, 2005.

MARCELO, Carlos. Políticas de inserción a la docencia: De eslabón perdido a puente para el desarrollo profesional docente. 2006. Disponível em: <http://preal.org/ ENGL/BusquedaNN.asp>. Acesso em: 12 out. 2010.

. Formação de Professores - para uma mudança educativa. Porto: Porto Editora, 1999.

AUTOR. Título. Local: Editora, ano.

Título. In: ROMANOWSKI, Joana Paulin; JUNQUEIRA, Sérgio Rogério Azevedo; MARTINS, Pura Lucia Oliver. (Orgs.). Conhecimento local e conhecimento universal: pesquisa, didática e ação docente. Curitiba: Champagnat, 2004. Páginas. NONO, Maévi Anabel; MIZUKAMI, Maria da Graça Nicoletti. Processos de Formação de Professoras Iniciantes. 2006. Disponível em: <http://www.anped.org.br>. Acesso em: 10 jul. 2010.

NóVOA, Antônio. Formação de Professores e Trabalho Pedagógico. Lisboa: Educa, 2002.

OLIVEIRA, Dalila Andrade. El trabajo docente y la nueva regulación educativa en América Latina. In: FELDFEBER, Myriam; OLIVEIRA, Dalila Andrade. (Comps.). Políticas educativas y trabajo docente. Buenos Aires: Centro de Publicaciones Educativas y Material Didáctico, 2006. 17- 31.

PERONI, Vera Maria Vidal; OLIVEIRA, Regina Tereza Cestari; FERNANDES, Maria Dilnéia Espíndola. Estado e Terceiro Setor: as novas regulações entre o público e o privado na gestão da educação básica brasileira. Educ. Soc., Campinas, CEDES, v. 30, n. 108, p. 761-778, out. 2009.

PORTELLA, Vanessa. Residência docente: um programa em desenvolvimento. In: Congreso Internacional sobre Profesorado Principiante e Inserción Profesional a la Docencia, 3, 2012, Santiago do Chile, Anais..., Santiago do Chile: UA. 1 Cd-Rom.

SANTOS, Oder José dos. Reestruturação capitalista: educação e escola. Trabalho \& Educação, Belo Horizonte, FaE/UFMG, v. 13, n. 1, 70-89, jan.-jul. 2004.

. Pedagogia dos conflitos sociais. Campinas: Papirus, 1992.

SHIROMA, Eneida Oto; CAMPOS, Roselane Fátima. La resignificación de la democracia escolar mediante el discurso gerencial: liderazgo, gestión democrática y gestión participativa. In: FELDFEBER, Myriam; OLIVEIRA, Dalila Andrade. (Comps.). Políticas educativas y trabajo docente. Buenos Aires, Centro de Publicaciones Educativas y Material Didáctico, 2006. 221-237.

STIVANIN, Neridiana Fabia; ZANCHET, Beatriz Maria Boessio Atrib. Docentes universitários iniciantes: percepções sobre um programa de inserção à docência. In: Congresso Internacional sobre Profesorado Principiante e Inserción Profesional a la Docencia, 3, 2012, Santiago do Chile, Anais..., Santiago do Chile: UA. 1 Cd - Rom. 
THOMPSON, Edward Palmer. A miséria da teoria ou um planetário de erros. Rio de Janeiro: Zahar Editores, 1981.

YANNOULAS, Silvia Cristina; OLIVEIRA, Talita Santos. Avatares de Prometeu: duas décadas de avaliação e regulação das políticas educacionais. Linhas Críticas, Brasília, UnB, v. 19, n. 38, 71-88, jan.-abr. 2013.

Recebido em março de 2014

Aprovado em maio de 2014

Silmara de Oliveira Gomes Papi é doutora em Educação pela Pontifícia Universidade Católica do Paraná, professora do Departamento de Educação da Universidade Estadual de Ponta Grossa e pesquisadora do grupo Política Educacional e Formação de Professores. E-mail: silmarapapidgmail.com

Pura Lúcia Oliver Martins é doutora em Educação pela Universidade de São Paulo, professora titular do Programa de Pós-Graduação em Educação e coordenadora da linha de pesquisa Teoria e Prática na Formação de Professores. E-mail: pura. oliverapucpr.br 